\title{
Short-term Technical Predictive Ability in the Taipei Stock Market
}

\author{
Yi-Jang $\mathrm{Yu}^{1}$ \\ ${ }^{1}$ Department of Economics, Ming-Chuan University, Taiwan, R. O. C. \\ Correspondence: Yi-Jang Yu, Department of Economics, Ming-Chuan University, 5 Der Ming Rd., Gui Shan \\ District, Taoyuan County 333, Taiwan, R. O. C. E-mail: yjyu@mail.mcu.edu.tw
}

Received: May 25, 2015

Accepted: June 10, 2015

Online Published: June 16, 2015

doi:10.5430/rwe.v6n2p50

URL: http://dx.doi.org/10.5430/rwe.v6n2p50

\begin{abstract}
Based on the principle of supply and demand, the rules of marginal change, the hypothesis of log-normal distribution, and the two-dimensional rules of performance evaluation, an effective WINDEX can be created to determine the momentum behind the price or index movement. Accordingly, by using the Taipei stock market as an example, not only a simple bounded WINDEX approach can be practiced to generate significant performance for the sample stock, but also an early warning system can be effectively constructed in the market. The phenomenon of knowledge asymmetry is a natural outcome of professional cooperation. Constructing an appropriate WINDEX involves its own professional knowledge. It involves little regarding market efficiency in information and more regarding knowledge asymmetry. Once this type of professional knowledge begins to spill over, its effect must be marginally diminished.
\end{abstract}

Keywords: technical predictive ability, WINDEX, early warning system, knowledge asymmetry

\section{Introduction}

If only trends of stock price are analysed, conclusions regarding random walk can be easily made by statisticians (Miller, 1999). If only charts of stock price movement patterns are studied, criticisms of being overly subjective can be easily levied (Jegadeesh, 2000). Technical analysis seems to be regarded as an outdated approach. However, after having prevailed in the early 1990s, technical analysis has again begun attracting a growing interest (Metghalchi \& Glasure, 2007).

For a long time, supporters of technical analysis were not able to refute the accusation of having no predictive power by proponents of fundamental analysis (Park \& Erwin, 2007), or provide a solid theoretical economic foundation for legitimising their analytical tools. (Note 1) Certain scholars have argued that, regarding the stock market, fundamental and technical analysis can complement each other (Talati, 2002). However, it remains necessary to prove that technical analysis can have short-term predictive ability. Brock et al. (1992) stated that predicting asset price changes must be facilitated by nonlinear random processes behind price movements. This implies that the short-term predictive ability of technical analysis can be effectively elaborated once the momentum behind stock price movement can be determined.

The aims of this study were two-folds. The first was to explain why technical predictive ability can exist in the stock market; this aim is explained on the basis of economic reasoning including the principle of supply and demand. The second aim was to demonstrate how the short-term predictive ability of technical analysis can be applied, by taking the Taipei stock market as an example. Finally, the controversy regarding the market efficiency hypothesis is discussed.

\section{Theoretical Foundation}

Every technical analysis of the stock market must involve first identifying the degree of immaturity of the stock been analysed. This is because no rational analytical tool can be applied for highly immature stocks with high price volatility. Under this circumstance, only a mechanical stop-loss approach can be considered, and the key to its success is to identify the optimal levels of stop-loss (Yu, 2007).

If analysis is regarded as an informational type of production line, even if extremely fine machinery is installed, the chances to obtain accurate output remain low if the wrong input is used. For example, a curve showing constant increments such as $(5,6,7,8,9)$ or marginally increasing increments such as $(5,6,7.1,8.3,9.6)$ can be interpreted as 
exhibiting constant or aggressive growth, respectively. However, if the values were expressed as percentages, the curves would represent a series of marginally decreasing values $(0.2,0.17,0.143,0.125)$ or $(0.2,0.183,0.169,0.157)$, respectively. Therefore, the appropriate input for application in stock analysis must combine the merits of both types of measurement. This is why Loh (2007) suggested that, rather than identifying the trends of stock prices, a confirming indicator should be determined.

In allegorical terms, if patients can have relevant knowledge, they are likely to accept the necessity of taking a certain drug only after believing that it is effective. Stock investment is a type of economic activity. Therefore, investors should be skeptical when applying certain technical analytical tools that are not sufficiently supported by economic theories.

Regarding the quantitative definition of individual stock, usually the expected rate of return is applied to achieve an equal performance evaluation. However, the reason for choosing standard deviation to represent asset risks must be explained in detail.

Stock price movements generally entail two scenarios, namely, all possible outcomes and corresponding probabilities of occurrence. Because individual probability is difficult to measure, a hypothesis of probability distribution should be considered. Numerous studies of the asset market have suggested that the hypothesis of lognormal distribution is acceptable (Jarrow \& Turnball, 1996; Limpert et al., 2001). This means, if asset prices or its rates of return could be transformed into logarithmic measures, the frequencies of prices or the rates of return within an appropriate sample period of time would be equivalent to the probability distribution of the subsequent prices or rates of return, respectively, and could be shown to have a shape of normal distribution. Clearly, this hypothesis is applicable to rational assets.

Assuming an asset price in a subsequent period can be expressed in the logarithmic form as $\widetilde{P}_{1}$ or its rate of return as $\widetilde{r}_{1}$ and the corresponding normalised probability density function as $f$, the expected value will be $E\left(\widetilde{P}_{1}\right)$ or $E\left(\widetilde{r}_{1}\right)$, respectively. After selecting a threshold as $P^{*}$ or an opportunity cost as $r_{f}$, the loss set can be defined as all possible results that are inferior to $P^{*}$ or $r_{f}$ and is the area on the left side of $P^{*}$ or $r_{f}$ beneath the curve representing $f$. When this area decreases, which means a reduced standard deviation $\sigma$ for $f$, the risk of the asset also decreases. For convenience, it is thus suggested that $\sigma$ can be taken to represent asset risk. However, the following premise must be valid: $P^{*}$ or $r_{f}$ has to be located on the left side of $E\left(\widetilde{P}_{1}\right)$ or $E\left(\widetilde{r}_{1}\right)$.

\subsection{Principle of Supply and Demand}

Using the Taipei stock market as an example, the awareness of environmental protection still has insufficient support from investors. This means that major incentives in this market are still confined within two rudimentary behaviours, earning as much as possible and losing as little as possible. Technical analysis of this market can be effectively conducted on the basis of these two incentives.

Simplicity makes technical analysis a widely used tool in stock markets worldwide. Fundamental analysis involving the supply side in both microeconomics and macroeconomics is usually practicable for professional investors. Nonetheless, according to the concept of market equilibrium, studying market data is equivalent to analysing the market content of supply-side data which, in turn, must conform to the market content of demand-side data. The only disadvantage is that, no fundamental predictive ability can be elaborated by analysing market data. Nonetheless, as long as the momentum behind price movement can be effectively determined, there remains a possibility to achieve short-term predictive ability through making technical analysis.

If only two major incentives of investment are concerned, linking them to the momentum behind the stock price movement must be the key to theoretically establishing short-term predictive ability in the stock market. By measuring the (logarithmic) expected rate of return $(E)$ and the corresponding standard deviation $(\sigma)$, each stock is defined as a point in the " $\sigma-E$ " plane. The next task is merging both measures into the momentum of price movement, and this task must correspond to the method of evaluating stock performance. When changes in either $E$ or $\sigma$ can be independent and possibly contradictive, a standard tool of evaluation must be applied to deliver a final conclusion.

\subsection{Two-dimensional Rules of Dominance}

Because both $\sigma$ and $E$ are heterogeneous products, the easiest way to merge them is to apply division (Yu, 2012). 
In statistics, $\sigma / E$ is called "coefficient of variation"; in economics, $E / \sigma$ can be interpreted as "the expected rate of return to be acquired on average by assuming one unit of an asset's total risk." However, it is only rational to bear risk when a rate of return higher than the opportunity cost is expected. Therefore, $E / \sigma$ must be modified to become $\left(E-r_{f}\right) / \sigma$ which in turn coincides with the Sharpe ratio.

However, a negative Sharpe ratio cannot be interpreted with reasonable economic meaning (Israelsen, 2005) unless short sales are allowed (Sharpe, 1994). Furthermore, the per-unit total risks for various assets are heterogeneous by nature and not directly comparable. Applying the hypothesis of lognormal distribution, Cheng (2002) suggested further transforming $\left(E-r_{f}\right) / \sigma$ into a cumulative probability measure that can be expressed as $N\left[\left(E-r_{f}\right) / \sigma\right]$. By definition, this measure is a cardinal number and can make evaluating various assets manageable. To be interpreted as the possibility of success in performing superiorly to the opportunity cost $r_{f}$, this measure is thus called WINDEX.

\subsection{Lognormal Probability Distribution Hypothesis}

Because WINDEX is a measure of cumulative probabilities, its range can only be [0,1]. High frequencies of (daily) rates of return should occur around a WINDEX value of 0.5 . Therefore, according to the hypothesis of lognormal probability distribution, the confidence of identifying extreme WINDEX values can thus be assured as long as the WINDEX does not fluctuate abnormally. Abnormal price fluctuations are rare for rational stocks. Therefore, even adopting a simple bounded WINDEX approach can enable investors to achieve a significant performance on investment. However, occasionally, the stock being analysed can become too stabilised. When this happens, the initial upper and lower bounds must be narrowed in synchronisation. Otherwise, the upper or lower bound can be missed. For rational stocks, the variation on price volatility can be highly stable, and observing the needed signals for required adjustment in advance is not difficult.

The next crucial task involves determining the optimal lower and upper bounds of WINDEX. This can be achieved through simulation tests. However, the aim of this study was to prove that short-term technical predictive ability actually exists instead of finding the best predictive ability; therefore, only convenient designs are suggested. WINDEX approaches vary considerably. A bounded approach is probably the simplest.

\section{Simulation Results Based on the Bounded WINDEX Approach}

In Appendix I, the used sample stock is the 2801Chang Hwa Bank (CHB) listed on the Taipei stock market. All closing prices were acquired through the internet from the Securities and Futures Institute of Taiwan. Columns A and $\mathrm{B}$ contain dates and closing prices, respectively; cell $\mathrm{C} 1$ represents an identical daily opportunity cost; all remaining numbers in the same column are (logarithmic) daily rates of return. For example, in cell C3, the programming language is: "=LN(B3/B2)." Column D is the size-30 WINDEX. For example, cell D32 is calculated on the basis of 30 daily rates of return prior to and including the date 2002/2/26; the programming language is: "=NORMSDIST $((A V E R A G E(\$ C 3: \$ C 32)-\$ C \$ 1) / \operatorname{STDEV}(\$ C 3: \$ C 32)) "$; Finally, the cells E32 and F32 are the arbitrarily determined lower and upper bounds of WINDEX.

\subsection{Short-term Predictive Ability of WINDEX}

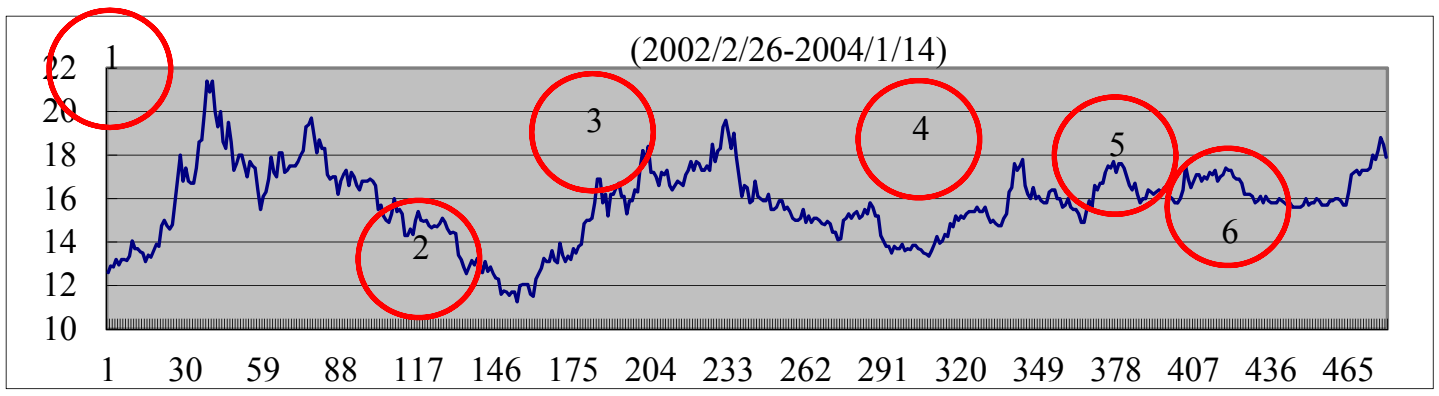

Figure 1. stock price (CHB) 


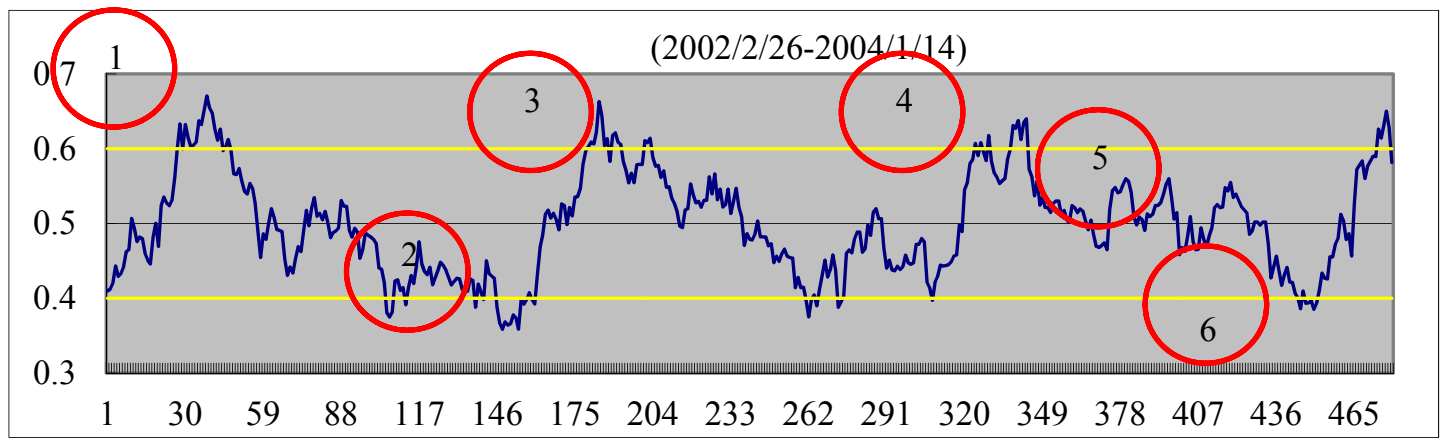

Figure 2. Size-30 WINDEX (CHB)

For the first part of the simulation test, the sample period lasted from 2002/1/4 to 2004/1/14. Both price and WINDEX charts of CHB during this sample period are shown in Figures 1 and 2, respectively. Both charts exhibit a sufficiently high similarity; no further effort in identifying a superior WINDEX chart was made.

As shown in Figure 1, because the stock price does not exhibit any boundary of movement except the $\pm 7 \%$ price change limitation regulated in the Taipei stock market, predicting the next local high (low) price is not easy. However, according to Figure 2, when the upper bound of 0.6 is broken through or the lower bound of 0.4 is perforated, the signal indicating selling or buying is executed immediately.

As shown in Figure 2, unlike in circles \#1 or \#2, circle \#3 exhibits a significant time lag, compared with circle \#3 in Figure 1. This indicates the use of an imperfect WINDEX. However, because the final outcome of the simulation test can still be satisfactory, this imperfection was disregarded. When the upper bound 0.6 in Figure 2 is broken through again, the "short" signal is still executed immediately, if a new high price is confronted. This is a widely used strategy for lowering the unit cost of investment. A similar circumstance can be observed in circle \#4, Figure 2.

Regarding circles \#5 and \#6 in Figure 1, the trend shows that the price movement is regulated. However, circle \#6 in Figure 2 reveals that, long before the price trend in Figure 1 begins to move upward, the WINDEX trend moves away from the middle line of 0.5 and hits the lower bound.

\subsection{Rules of the Game}

Although the upper and lower bounds of WINDEX are selected arbitrarily, as long as they can be applied to achieve a satisfactory performance in simulation tests, fine tuning can be performed in the future. Based on these two upper and lower bounds, the operational rules in the simulation test for $2801 \mathrm{CHB}$ during the sample period can be listed as: "whenever the size-30 WINDEX reaches the lower (upper) bound, close the short position and buy (sell and short); each time, only one more unit is added when the upper (lower) bound is reached again and a new local high (low) is observed; however, the number of making additional units is not limited."

For convenience, no transaction cost was considered. Because transaction costs are already considerably low in the Taipei stock market, unless the outcome of simulation tests is unfavourable, its impact cannot be high. In addition, although the CHB issued 0.4 cash dividends in 2002, it stopped in 2003. Therefore, again, for convenience, the problem of issuing dividends was neglected in this study. Finally, all transactions were assumed to be executed exactly at the closing prices.

\subsection{Simulation Results}

Based on the stated rules of the game, all primary information and execution strategies are listed in Appendix II for the sample period of 2002/2/26-2004/1/14. First, on the date 2002/2/26, the size-30 WINDEX was 0.4099 and shown a rising trend. Although already having certain disadvantages, buy at the closing price was determined. On 2002/4/4, the WINDEX reached the upper bound 0.6 , sell and short. On 2002/4/10 or 5/2, the WINDEX rebounded again and crossed the upper bound 0.6 before reaching the next lower bound, each time short one more unit. On 2002/7/25, the WINDEX reached the lower bound 0.4, closing all three short positons and buying one more unit.

Finally, on 2004/1/14, close the long position established on 2003/12/3. The performance exhibited a net of 32.1 or approximately $250 \%$ rate of return on investment. By contrast, when buying at the beginning at 12.6 , holding, and selling at the end at 18, the net was 5.4. The significant outcome was contributed from the sufficiently perfect Figure 2 that could reach the lower and upper bounds whenever required. Whether this significant performance can be continued merits investigation. 
By setting a similar sample period of 2 years and applying the same rules, the simulation outcomes for the next 10 years for CHB are: 6.95 in 2004-06, 16.35 in 2006-08, 9.55 in 2008-10, 11.35 in 2010-12, and 9.6 in 2012-14. In contrast to the simple buy and hold strategy: -1.5 in 2004-06, 2.05 in 2006-08, -3.1 in 2008-10, 1.65 in 2010-12, and 2.15 in 2012-14, the differences are significant. This strongly suggests that the bounded WINDEX approach exhibits a short-term predictive ability, especially regarding matured stocks.

According to Appendix III, the standard deviations, measured on the basis of 1-year daily rates of return, occasionally fall below an arbitrarily selected level of 0.02 . This could explain why the size- 30 WINDEX did not cross the upper or lower bounds when it should have, and hence affected the performance of the simulation test negatively. Both the lower and upper bounds must be narrowed when the standard deviation falls below the threshold of 0.02 .

Because the changes of standard deviation are stable in Appendix III, detecting its level falling below 0.02 and resetting both the lower and upper bounds is not difficult. Again, for convenience, new bounds were set at 0.45 and 0.55. The new Rules are almost similar; except that if the old bounds of 0.6 and 0.4 were crossed, old rules should be applied in addition. The new performance can be: 14 in 2004-06, 13.5 in 2006-08, 13.2 in 2008-10, 17.9 in 2010-12, and 12.45 in 2012-14. Only the performance in 2006-08 was not improved. Careful examination provided in Appendix III reveals that on 2006/10/14, the standard deviation already bounced back to 0.02; applying new rules would cause unfavourable outcomes as a consequence. A high possibility would be the inappropriateness of setting the threshold at 0.02 . Nevertheless, to narrow the required bounds in synchronisation with a reduced standard deviation is necessary.

\section{Early Warning System of the Stock Market}

The earning warning system (EWS) in the financial market was probably based on the study of behaviour management of brokers (Altman \& Loris, 1976). Later, it was expanded to the study of banking management (Pettway \& Sinkey, 1980), and subsequently, financial crises (Summers, 2000), monetary crises (Fratzscher, 2003), and other fields. Regarding the stock market, a substantial slide without warning can always cause economic loss and a crisis of confidence. Recent related studies have indicated several causes of occurrence, including the co-movement of international stock markets and the herding behaviour in the stock markets. However, the suggestions of EWS are still limited to issues concerning severe crashes in international stock markets (Sornette \& Zhou, 2006; Barisik \& Tay, 2010).

\subsection{Reasons for Substantial Slides without Warning in the Stock Market}

According to previous studies, the reasons causing substantial slides without warning in the stock market can be classified into the following four categories. The first includes non-economic systematic factors such as natural disasters (Worthington \& Valadkhani, 2004), terrorist attacks (Brounen \& Derwall, 2010), the risk of war (Rigobon \& Sack, 2005), political events (Berkman et al., 2011), and major epidemics (Chen et al., 2009). Whether originated internally or externally, these factors can exert substantial pressure on investment confidence. However, this category was not investigated in this study.

The second category includes economic systematic factors, and can be further divided into the following two subsets. In the domestic category, the focus is on how changes in interest rates (Jawadi et al., 2010), exchange rates (Walid et al., 2011), monetary supplies (Chao et al., 2011), and GDP (Dermirhan et al., 2011) can have substantial impacts on domestic stock markets. In the foreign category, the focus is mainly on the co-movement among certain international stock markets (Fan et al., 2009; Oh et al., 2010). However, especially in the domestic category, because of data limitations, only monthly data can be applied for analyses (Liu \& Shrestha, 2008). In the foreign category, predominantly weekly data of market indexes were used for analyses (Capragle \& Spagnolo, 2011). Neither is appropriate for studying EWS with a daily requirement; hence, they were not investigated in this study.

The third category represents herding behavior in the stock market. This means that an incurred blind psychology encourages investors to act as a herd, potentially causing markets to crash (Levy, 2008; Park, 2011). However, if there is no standard analytical approach available, applying various methods of analysis can lead to various outcomes (Demirer et al., 2010). Moreover, new ideas are still tested for their efficacy, including adding the factor of co-movement of international stock markets (Chiang \& Zheng, 2010). However, this was not investigated in this study.

The last category refers to the factor that can cause structural changes in the stock market. This factor has been described as a natural phenomenon occurring everywhere, including the stock market, and is initially proposed in physics, where co-movement and phase transition are considered natural phenomena associated with every organic 
and artificial structure. Accordingly, the new discipline ecophysics was established (Preis, 2011); keywords include co-movement and phase transition (Scheffer et al., 2009). This new field was the focus of this study.

The fourth category can be further differentiated into two subsets (Barberis, 2005). The first concerns factors that can be driven by fundamental information, the second concerns factors that can be driven by investor sentiment and market frictions, reflecting the aforementioned second and third categories. Furthermore, only related studies concerning long-term real business cycles and real industry co-movements were found (Hornstein, 2000; Chan et al., 2007). According to our research, no studies have addressed the co-movement of industry indexes. This study demonstrates that, after confirming indicators for each individual industry index can be effectively constructed, analysing the phenomenon of co-movement plus phase transition in the stock market on the basis of industry indexes becomes viable.

In this study, co-movement means that there can be gradually more industry indexes moving upward. Basically, although the market index is composed of all its member stocks, it can also be regarded as composed by all its individual industry indexes. Clearly, it is considerably simpler to work with a far lower number of individual industry indexes than with a high number of individual stocks.

Phase transition means that most co-moving industry indexes can simultaneously or almost simultaneously reach their local highs and reverse their movements immediately after that. Because investors are still unaware of this type of structural changes, substantial slides in the market can occur without warning. Although cycles of rise and fall among various industry indexes can vary widely, this phenomenon of co-movement plus phase transition can still occur occasionally and naturally. In the Taipei stock market, for example, during the observation period, the longest cycle of rise and fall within the applied WINDEX for an individual industry index is no longer than 2 months; therefore, the occurrence of co-movement plus phase transition should not be rare.

\subsection{Standard 3-day Co-movement plus Phase Transition}

Regarding the Taipei stock market, 11 new industry indexes have been added to the list since 2007/7/2. Therefore, the entire sample period lasted from July 2007 to December 2012 to prevent data inconsistency. For convenience, in this study, only one certain pattern of co-movement plus phase transition was investigated to explain the method for establishing the EWS. All industry indexes were acquired through the internet from the Securities and Futures Institute of Taiwan, Info on Companies Listed on the TWSE, and Daily TSEC Weighted Stock Price Index (Group), and missing data was recorded on 2008/5/19 and 2012/6/29. Therefore, the sample market index data was trimmed to maintain consistency.

First, during the observation period, WINDEX cycles observed for all industry indexes were mostly between 15 and 37 days. Therefore, longer-term WINDEX averages were chosen to enable an improved dilution of temporary interferences. Accordingly, the N-W (14 to 23) average WINDEX was applied uniformly for all 28 industry indexes. Unless applying various designs of WINDEX for various industry indexes could be rationalised, unified practice would be preferred.

Table 1 . Sum of industry indexes in the up or down category

\begin{tabular}{|c|c|c|c|c|c|c|c|c|c|c|c|c|c|}
\hline Date & High & Low & Close & Cement & WINDEX & Up & Down & Others & WINDEX & Up & Down & \multicolumn{2}{|c|}{ Sum of indexes } \\
\hline & & & & & & & & & & & & Up & Down \\
\hline $2012 / 10 / 17$ & 7,518.36 & $\mathbf{7 , 4 5 0 . 2 9}$ & $7,464.40$ & 125.14 & 0.4944 & $\mathbf{0}$ & 125.14 & 186.6 & 0.5341 & 0 & 186.57 & 533.44 & 5171.28 \\
\hline $2012 / 10 / 18$ & $7,495.45$ & $7,448.06$ & $7,465.41$ & 125.05 & 0.4890 & $\mathbf{0}$ & 125.05 & 187.6 & 0.5476 & 187.6 & $\mathbf{0}$ & 1736.03 & 3966.88 \\
\hline 2012 & $7,465.41$ & $7,402.66$ & $7,408.76$ & 126.81 & 0.5253 & 26.81 & $\mathbf{0}$ & 187.1 & 344 & $\mathbf{0}$ & 187.13 & 12 & 6.41 \\
\hline $2012 / 10 / 22$ & $7,408.76$ & $7,310.79$ & $7,373.04$ & 127.04 & 0.5320 & 127.04 & 0 & 186.1 & 0.5071 & $\mathbf{0}$ & 186.11 & 469.29 & 5178.18 \\
\hline $2012 /$ & $\mathbf{7 , 3 7 5 . 5 0}$ & $7,326.39$ & $7,337.48$ & 125.96 & 0.5095 & 0 & 125.96 & 184.5 & 0.4712 & 0 & 184.53 & 495.85 & 5123.27 \\
\hline $2012 /$ & $7,348.45$ & $\mathbf{7 , 2 7 4 . 8 8}$ & $7,314.88$ & 126.09 & 0.5134 & 26.09 & 0 & 184.4 & 0.4617 & 0 & 184.4 & 1278.48 & 4314.03 \\
\hline $2012 / 10 / 25$ & $7,339.21$ & $7,260.00$ & $7,262.08$ & 126.65 & 0.5249 & 126.65 & 0 & 182.7 & 0.4282 & 0 & 182.68 & 1405.85 & 4149.63 \\
\hline 2012 & $7,298.48$ & 7,1 & 7,13 & 123.08 & & 0 & 123.08 & 178.5 & 81 & 0 & 178.46 & 436.57 & 4988.2 \\
\hline $2012 /$ & $7,165.10$ & $7,091.19$ & $7,091.67$ & 123.8 & 0.4754 & 123.8 & 0 & 178.3 & 0.3687 & 0 & 178.29 & 587.95 & 4802.98 \\
\hline $2012 / 10 / 30$ & $7,206.35$ & $7,091.67$ & $7,182.59$ & 125.45 & 0.5008 & 125.45 & 0 & 178.8 & 0.3679 & 0 & 178.81 & 5157.87 & 294.28 \\
\hline 2012 & $7,222.84$ & $7,139.17$ & $7,166.05$ & 125.46 & & 125.46 & 0 & 177.7 & & 0 & 177.74 & 2284.45 & 3162.19 \\
\hline $2012 / 11 / 1$ & $7,188.23$ & $7,050.05$ & $7,179.64$ & 124.07 & 0.4873 & 0 & 124.07 & 178.1 & 0.3520 & 178.1 & 0 & 4195.62 & 1247.38 \\
\hline $2012 / 11 / 2$ & $7,235.13$ & $7,179.64$ & $7,210.47$ & 125.53 & 0.5123 & 125.53 & 0 & 178 & 0.3479 & 0 & 177.96 & 4663.12 & 812.05 \\
\hline
\end{tabular}

Table 1 features the columns "Date" followed by "High," "Low," "Close" of the market index and the close of the first industry "Cement," its N-W average WINDEX, and the close of the Cement industry that is duplicated by following the corresponding sign of WINDEX if it moves up or down from the previous day. All other industries and their indexes were similarly arranged until the last and 28th industry "Others." Finally, the sums of all industrial 
indexes that are classified as "Up" or "Down" were calculated.

The structure revealing a 3-day co-movement is discussed in the following. For example, for the three consecutive trading days 2012/10/26, 29, and 30, the sum of rising indexes increased from 436.57 to 587.95 and then to 5157.87, and subsequently reversed. The requirement is that, on the third day $(2012 / 12 / 30)$, the sum of rising indexes had to be greater than the sum of falling indexes. The reversed situation is what the signal of "phase transition" would indicate with a similar requirement but in a reversed pattern. Basically, because most industry indexes fell only slightly on the fourth day, together they caused little negative impact on the market. However, on the subsequent day, based on the principle of marginal change plus a possible cause of herding behaviour, the market slid more than $1 \%$ from the close of 7166.5 on 2012/10/30 to the low of 7050.05 on 2012/11/1. The reasons for not using the close of 7179.64 on 11/1 were first, to prevent any possible rebound before the market closed; and second, to reflect the fact that the prediction of having a slide approximately equals to 7166.5 minus 7050.05 could already be made right at or near the close on 10/30.

One problem is that the exact time of detecting a phase transition cannot be easily identified when only limited price data was observed. Therefore, if any phase transition occurs long before the market closes, it has to be treated as a different type of signal structure, rather than as a standard type. In this study, the exceptions are those cases whose deviations between the high and the low on the fourth day are more than $1 \%$, indicating that earlier phase transitions occurred. Similarly, other types featuring more than 3-day co-movement plus phase transition are treated as different signal structures and remain as future interest. As shown in Appendix IV, within the sample period, 24 cases were available, and half of them drove the market to fall more than $1 \%$ and the other half drove the market to fall less than $1 \%$.

Finally, obtaining the structure of signals for the standard 3-day co-movement and phase transition was attempted by applying all data shown in Appendix IV. Based on the variables defined in the appendix, for 3-day co-movement three variables are suggested to represent its signal structure in an integrated sense. They include $x_{2}$ and $x_{3}$, which are set as $\left(a_{2}-a_{1}\right) /\left(a_{1}+b_{1}\right)$ and $\left(a_{3}-a_{2}\right) /\left(a_{2}+b_{2}\right)$, respectively. The other variable is $x_{1}$ relating to the initial value of $a_{1}$, and dummy variables are suggested because of insufficient samples. The current suggestion is that if the ratio of $a_{1}$ to $a_{1}+b_{1}$ is lower than 5\%, the dummy is set to be 0 ; if the ratio is between $5 \%$ and $20 \%$, the dummy is 1 ; if the ratio is higher than $20 \%$, the dummy is 2 . Regarding the signal of the phase transition, variable $x_{4}$ is suggested to be $\left(a_{3}-a_{1}\right) /\left(a_{1}+b_{1}\right) * L N\left(a_{3}+b_{4}\right)$. The outcomes from a simple OLS test can thus be presented as

$$
\begin{aligned}
& Y=0.022-0.039 X_{1}-0.384 X_{2}+0.0386 X_{3}-0.0075 X_{4} \quad F=3.25 \quad R^{2}=0.41 \\
& \begin{array}{lllll}
(0.058) & (0.0145) & (0.0153) & (0.0224) & (0.0499)
\end{array}
\end{aligned}
$$

Individual $P$-values and the $F$-value can all reach a significant level of $5 \%$. However, the explanatory power for the whole model remains lower than $50 \%$. Seeking an additional explanatory variable or acquiring more data were not the main interest of this study and remain aims for future research.

\section{Efficient Market Hypothesis}

The term "data" has been defined as numbers, characters, voices, pictures, etc., and the term "information" has been defined as those data that can be rearranged to have economic values (Davis \& Botkin, 1999). Kermally (1999) suggested that knowledge can include data, information, culture, ideas, and beliefs. Therefore, even if any received information was identical, the final opinions and conclusions can still vary among people. At present, knowledge asymmetry remains a common phenomenon in our society and is a natural consequence of professional specialisation.

When Samuelson (1965) proposed the concept of an efficient capital market, he merely thought that an efficient capital market should not have any artificial barriers in the process of information publication and circulation. Fama (1976) emphasised that in an efficient capital market every asset price should reveal all available information in the market perfectly. However, mainly the lack of knowledge efficiency, rather than information efficiency, can cause disturbances in beliefs in the market (Block, 1999; Thomas III., 2000).

Among investors, in addition to having various opportunity costs of collecting and sorting information, their conclusions and judgments can differ according to the following two main reasons. The first is the degree of risk aversion affecting a person's investment strategy (Lo, 1999). The second relates to a person's professional 
knowledge; most related studies have favoured an agent-based model (Famer \& Lo, 1999). This model emphasises that the market is a common environment for competition and evolution and the result of adjustment and innovation from individual investors' self-learning. Therefore, as long as new investment strategies can continuously emerge, market efficiency can be improved accordingly, and no efficient market can be expected.

Regarding stock investment, applicable knowledge for the various forms of historical, open, and private information defined in Fama (1976) must vary. For example, if company information and hence, fundamental analysis, is concerned, an asset pricing system must be applied ( $\mathrm{Yu}, 2012)$. Therefore, because technical analysis can contribute short-term prediction capability, and the fundamental analysis can contribute long-term prediction capability, both methods should complement each other. Moreover, both methods represent professional knowledge in the stock market and are created on the basis of knowledge asymmetry.

\section{Conclusion}

The major shortcoming of technical analysis in the stock market is that its predictive ability has never been sufficiently supported by economic theories. Stock investment is definitely a type of economic activity. If the applied analytical tool cannot be supported by certain economic theories, its efficacy remains questionable. On the basis of economic theories and concepts, this study suggests that the method for effectively determining the momentum of price movement is viable, especially for matured stocks. The assertion that "the value of technical analysis should be positively correlated with volatility" (Sturm, 2013, p.12) can be regarded as a small oversight. This is because, if an expected price cannot be trusted, no rational analysis can be achieved.

Stock analysis should be considered a type of information transformation. Therefore, inappropriate inputs preclude the possibility of obtaining quality products. Stock prices do not have limits of variation. By contrast, WINDEX is not only supported by economic theories and concepts but can also have a fixed boundary. By conforming to the hypothesis of lognormal probability distribution, the short-term predictive ability can be effectively exercised by having the property of identifying extreme WINDEX values. This is especially true for matured stocks whose momentum of price movement can be managed. As long as the stability of WINDEX volatility can be adequately maintained, even a bounded WINDEX approach can generate a significant performance.

By definition, the stock market is composed of either all member stocks or all classified industry indexes. Because the WINDEX cycle of ups and downs for every individual industry index in the Taipei stock market during the observation period was no longer than 2 months, the possibility of having an event of co-movement plus phase transition should not be rare. As long as the momentum of each industry index can be effectively represented by its WINDEX, events of structural changes in the stock market that can cause substantial slides without warning can be directly studied. Finally, a special type of 3-day early warning system can be established in the Taipei stock market. In sum, both the bounded WINDEX approach and the early warning system introduced in this study can be combined to prove the existence of short-term technical prediction ability in the Taipei stock market.

The phenomenon of knowledge asymmetry is a natural outcome of professional cooperation. Constructing an appropriate WINDEX involves its own professional knowledge. It involves little regarding market efficiency in information and more regarding knowledge asymmetry. Once this type of professional knowledge begins to spill over, its effect must be marginally diminished.

Finally, even if information and knowledge efficiency could be achieved perfectly in the stock market, moral or cultural asymmetry would still drive investors to act differently. We therefore believe that only the unification of morality can be the ultimate means of achieving true market efficiency.

\section{References}

Altman, E.I., \& Loris, B. (1976). A financial early warning system for over the counter broker dealers. Journal of Finance, 31(4), 1201-1217. http://dx.doi.org/10.1111/j.1540-6261.1976.tb01969.x

Barberis, N., Shleifer, A., \& Wurgler, J. (2005). Comovement. Journal of Financial Economics, 75(2), 283-317. http://dx.doi.org/10.1016/j.jfineco.2004.04.003

Barisik, S., \& Tay, A. (2010). An analysis of financial crisis by early warning approach: the case of transition economies and emerging markets (1994-2006) period panel logit model. International Journal of Economic Perspectives, 4(2), 403-426. Retrieved from http://search.proquest.com/docview/759257856?accountid=12469

Berkman, H., Jacobsen, B., \& Lee, J.B. (2011). Time-varying rare disaster risk and stock returns. Journal of Financial Economics, 101(2), 313-332. http://dx.doi.org/10.1016/j.jfineco.2011.02.019

Block, S.B. (1999). A study of financial analysts: Practice and theory. Financial Analyst Journal, 55(4), 86-95. http://dx.doi.org/10.2469/faj.v55.n4.2288 
Brock, W., Lakonishok, J., \& LeBaron, B. (1992). Simple technical trading rules and the stochastic properties of stock returns. Journal of Finance, 47(5), 1731-1764. http://dx.doi.org/10.1111/j.1540-6261.1992.tb04681.x

Brounen, D., \& Derwall, J. (2010). The impact of terrorist attacks on international stock markets. European Financial Management, 16(4), 585-598. http://dx.doi.org/10.1111/j.1468-036X.2009.00502.x

Caporale, G.M., \& Spagnolo, N. (2011). Stock market integration betwee three CEECs, Russia, and the UK. Review of International Economics, 19(1), 158-169. http://dx.doi.org/10.1111/j.1467-9396.2010.00938.x

Chan, W., Louis, K.C., Lakonishok, J., \& Swaminathan, B. (2007). Industry classification and return comovement. Financial Analysts Journal, 63(6), 56-70. http://dx.doi.org/10.2469/faj.v63.n6.4927

Chao, C., Hu, S., Tai, M., \& Wang, V. (2011). Monetary policy announcements and stock price dynamics in a small open economy. International Review of Economics \& Finance, 20(4), 520-531. http://dx.doi.org/10.1016/j.iref.2010.10.004

Chen, C., Chen, C., Tang, W., \& Huang, B. (2009). The positive and negative impacts of the SARS outbreak: A case of the Taiwan industries. Journal of Developing Areas, 43(1), 281-293. http://dx.doi.org/10.1353/jda.0.0041

Cheng, Y. (2002). The WINDEX View of Stock Investment. Master thesis of the Department of Economics, Ming Chuan University, Taoyuan, Taiwan.

Chiang, T.C., \& Zheng, D. (2010). An empirical analysis of herd behavior in global stock markets. Journal of Banking \& Finance, 34(8), 1911-1921. http://dx.doi.org/10.1016/j.jbankfin.2009.12.014

Davis, S., \&Botkin, J. (1999). The coming of knowledge-based business. In Tapscott, D., (Ed.), Creating Value in the Network Economy (pp. 3-12). MA:HBS.

Demirer, R., Kutan, A.M., \& Chen, C. (2010). Do investors herd in emerging stock markets?: Evidence from the Taiwanese market. Journal of Economic Behavior \& Organization, 76(2), 283-295. http://dx.doi.org/10.1016/j.jebo.2010.06.013

Dermirhan, E., Aydemir, O., \& Inkaya, A. (2011). The direction of causality between financial development and economic growth; Evidence from Turkey. International Journal of Management, 28(1), 3-20. Retrieved from http://search.proquest.com/docview/853332579?accountid=12469

Fama, E.F. (1976). Foundations of Finance. New York, NY: Basic.

Fan, K., Lu, Z., \& Wang, S. (2009). Dynamic linkages between the China and international stock market. Asia-Pacific Financial Markets, 16(3), 211-230. http://dx.doi.org/10.1007/s10690-009-9093-5

Farmer, J.D., \& Lo, A.W. (1999). Frontiers of finance: Evolution and efficient markets. Proceedings of the National Academy of Sciences of the United States of America, 96(18), 9991-9992. http://dx.doi.org/10.1073/pnas.96.18.9991

Fratzscher, M. (2003). On currency crises and contagion. International Journal of Finance \& Economics, 8(2), 109-129. http://dx.doi.org/10.1002/ijfe.203

Hornstein, A. (2000). The business cycle and industry comovement. Economic Quarterly - Federal Reserve Bank of Richmond, 86(1), 27-48. Retrieved from http://search.proquest.com/docview/204889165?accountid=12469

Israelsen, C. (2005). A refinement to the Sharpe ratio and information ratio. Journal of Asset Management, 5(6), 423-427. http://dx.doi.org/10.1057/palgrave.jam.2240158

Jarrow, R., \& Turnbull, S. (1996). Derivative Securities. Ch 4. Ohio, USA: South-Western.

Jawadi, F., Arouri, M.H., \& Nguyen, D.K. (2010). Global financial crisis, liquidity pressure in stock markets and efficiency of central bank interventions. Applied Financial Economics, 20(8), 669-680. http://dx.doi.org/10.1080/09603100903493195

Jegadeesh, N. (2000). Foundations of technical analysis: discussion. Journal of Finance, 55(4), 1765-1770. http://dx.doi.org/10.1111/0022-1082.00266

Kermally, S. (1999). When Economics Means Business: the New Economics of the Information Age. Great Britain: Pitman.

Levy, M. (2008). Stock market crashes as social phase transitions. Journal of Economic Dynamics \& Control, 32(1), 137-155. http://dx.doi.org/10.1016/j.jedc.2007.01.023

Limpert, E., Stahel, W.A., \& Abbt, M. (2001). Log-normal distribution across the sciences: Keys and clues. Bioscience, 51(5), 341-352. Retrieved from http://search.proquest.com/docview/216466200?accountid=12469 
Liu, M., \& Shrestha, K.M. (2008). Analysis of the long-term relationship between macro-economic variables and the Chinese stock market using heteroscedastic cointegration. Managerial Finance, 34(11), 714-755.

Lo, A.W. (1999). The three P's of total risk management. Financial Analysts Journal, 55(1), 13-26. http://dx.doi.org/10.2469/faj.v55.n1.2238

Loh, E.Y.L. (2007). An alternative test for weak form efficiency based on technical analysis. Applied Financial Economics, 17(12), 1003-1012. http://dx.doi.org/10.1080/09603100600749352

Metghalchi, M., \& Glasure, Y. (2007). On the profitability of technical analysis: Evidence from Greece. Business Review, 9(1), 237-241.

Miller, M.H. (1999). The history of finance. Journal of Portfolio Management, 25(4), 95-101. http://dx.doi.org/10.3905/jpm.1999.319752

Oh, S., Lau, E., Puah, C., \& Mansor, S.A. (2010). Volatility co-movement of ASEAN-5 equity markets. Journal of Advanced Studies in Finance, 1(1), 23-30. http://dx.doi.org/10.1016/j.jbankfin.2011.02.025

Park, B. (2011). Asymmetric herding as a source of asymmetric return volatility. Journal of Banking \& Finance, 35(10), 2657-2665. http://dx.doi.org/10.1111/j.1467-6419.2007.00519.x

Park, C.H., \& Erwin, S.H. (2007). What do we know about the profitability of technical analysis?. Journal of Economic Surveys, 21(4), 786-826. http://dx.doi.org/10.1111/j.1540-6261.1980.tb03476.x

Pettway, R.H., \& Sinkey, J.F. Jr. (1980). Establishing on-site bank examination priorities: an early-warning system using accounting and market information. Journal of Finance 35(1), 137-150. http://www.jstor.org/stable/2327186

Preis, T. (2011). Econophysics-complex correlations and trend switchings in financial time series. European Physical Journal Special topics, 194, 5-86. http://dx.doi.org/10.1140/epjst/e2011-01397-y

Rigobon, W., \& Sack, B. (2005). The effects of war risk on US financial markets. Journal of Banking \& Finance, 29(7), 1769-1789. http://dx.doi.org/10.1016/j.jbankfin.2004.06.040

Samuelson, P.A. (1965). Proof that properly anticipated prices fluctuate randomly. Industrial Management Review, $6(2), 41-49$.

Scheffer, M., Bascompte, J., Brock, W.A., Brovkin, V., Carpenter, S.R., Dakos, V., ... Sugihara, G. (2009). Early-warning signals for critical transitions. Nature, 461(7260), 53-59. http://dx.doi.org/10.1038/nature08227

Sharpe, W.F. (1994). The Sharpe ratio. Journal of Portfolio Management, 21(1), 49-58. http://dx.doi.org/10.3905/jpm.1994.409501

Sornette, D., \& Zhou, W. (2006). Predictability of large future changes in major financial indices. International Journal of Forecasting, 22(1), 153-168. http://dx.doi.org/10.1016/j.ijforecast.2005.02.004

Stiglitz, J.E. (2000). The contributions of the economics of information to twentieth century economics. The Quarterly Journal of Economics, 115(4), 1441-1475. http://dx.doi.org/10.1162/003355300555015

Sturm, R.R. (2013). Market Efficiency and Technical Analysis Can They Coexist. Research in Applied Economics, 5(3), 1-15. http://dx.doi.org/10.5296/rae.v5i3.4049

Summers, L.H. (2000). International financial crises. American Economic Review, 90(2), 1-16. http://dx.doi.org/10.1257/aer.90.2.1

Talati, J. (2002). Fundamental vs. technical analysis: Part 1. Futures, 31(1), 58-60. Retrieved from http://search.proquest.com/docview/235260057?accountid=12469

Thomas III., L. (2000). Active management. Journal of Portfolio Management, 6(2), 25-32. http://dx.doi.org/10.3905/jpm.2000.319739

Walid, C., Chaker, A., Masood, O., \& Fry, J. (2011). Stock market volatility and exchange rates in emerging countries: A Markov-state switching approach. Emerging Markets Review 12(3), 272-292. http://dx.doi.org/10.1016/j.ememar.2011.04.003

Worthington, A., \& Valadkhani, A. (2004). Measuring the impact of natural disasters on capital markets: an empirical application using intervention analysis. Applied Economics, 36(19), 2177-2186. http://dx.doi.org/10.1080/0003684042000282489

Yu, Y. (2007). Stock Analysis and Investment ( $2^{\text {nd }}$ ed., in Chinese). Taipei: Yeh-Yeh.

Yu, Y. (2012). The Asset Pricing System. Modern Economy, 3(5), 473-480. http://dx.doi.org/10.4236/me.2012.35062 


\section{Note}

Note 1. At most, "the theoretical foundation for technical analysis appears to be plausible as supported by Social Psychology, by the evidence that institutions and exchanges appear to value technical analysis and by major lines of academic research that have been created from studies using a technical approach.” (Sturm, 2013, p.10)

Appendix I. The WINDEX working sheet in EXCEL

\begin{tabular}{|c|c|c|c|c|c|c|}
\hline & $\overline{\mathbf{A}}$ & $\mathbf{B}$ & $\mathbf{C}$ & $\overline{\mathbf{D}}$ & $\mathbf{E}$ & $\mathbf{F}$ \\
\hline 1 & 2801 CHB & Close & 0.0001 & 30-average WINDEX & lower & upper \\
\hline 2 & $2002 / 1 / 4$ & 14.35 & & & & \\
\hline 3 & $2002 / 1 / 7$ & 14.65 & 0.02069 & & & \\
\hline 4 & $2002 / 1 / 8$ & 14.4 & -0.01721 & & & \\
\hline 5 & $2002 / 1 / 9$ & 14.35 & -0.00348 & & & \\
\hline$:$ & $:$ & : & : & : & $:$ & $:$ \\
\hline$:$ & $:$ & : & $:$ & $:$ & $:$ & $:$ \\
\hline 30 & $2002 / 2 / 22$ & 13.1 & -0.01515 & & & \\
\hline 31 & $2002 / 2 / 25$ & 12.6 & -0.03892 & & & \\
\hline 32 & $2002 / 2 / 26$ & 12.6 & 0 & 0.4099 & 0.4 & 0.6 \\
\hline 33 & $2002 / 2 / 27$ & 12.9 & 0.02353 & 0.4123 & 0.4 & 0.6 \\
\hline 34 & $2002 / 3 / 1$ & 12.85 & -0.00388 & 0.4205 & 0.4 & 0.6 \\
\hline 35 & $2002 / 3 / 4$ & 13.2 & 0.026873 & 0.4432 & 0.4 & 0.6 \\
\hline
\end{tabular}

Appendix II. Main events recorded from testing $2801 \mathrm{CHB}$

\begin{tabular}{|c|c|c|c|c|c|c|c|c|c|c|c|c|c|}
\hline Date & Tosing & WINDEX & $\left(1^{\text {st }}\right.$ act $)$ & $\left(2^{110}\right)$ & price & $+/-$ & Date & Closing & WINDEX & $\left(1^{\mathrm{st}}\right.$ act $)$ & $\left(2^{\ln }\right)$ & price & $+/-$ \\
\hline $2002 / 2 / 26$ & 12.6 & 0.4099 & Buy & & 12.6 & & $2002 / 12 / 9$ & 17.4 & 0.5788 & & & & \\
\hline $2002 / 4 / 4$ & 16.9 & 0.6002 & Sell & Short & 16.9 & 4.3 & $2002 / 12 / 10$ & 18.2 & 0.6105 & $\begin{array}{l}\text { Short } 1 \\
\text { more }\end{array}$ & & 18.2 & \\
\hline $2002 / 4 / 9$ & 16.8 & 0.5997 & & & & & $2003 / 3 / 14$ & 15.5 & 0.3985 & $\begin{array}{l}\text { Close } 3 \\
\text { units }\end{array}$ & Buy & 15.5 & 2.9 \\
\hline $2002 / 4 / 10$ & 17.4 & 0.6324 & Short 1 more & & 17.4 & & $2003 / 3 / 19$ & 14.9 & 0.4045 & & & & \\
\hline $2002 / 4 / 30$ & 18.6 & 0.5975 & & & & & $2003 / 3 / 20$ & 15.1 & 0.3901 & Buy 1 more & & 15.1 & \\
\hline $2002 / 5 / 2$ & 18.3 & 0.6026 & Short 1 more & & 18.3 & & $2003 / 3 / 31$ & 14.45 & 0.4379 & & & & \\
\hline $2002 / 7 / 25$ & 15 & 0.3808 & Close 3 units & Buy & 15 & 7.6 & $2003 / 4 / 1$ & 14.45 & 0.3880 & Buy 1 more & & 14.45 & \\
\hline $2002 / 8 / 2$ & 15.3 & 0.4144 & & & & & $2003 / 5 / 20$ & 13.45 & 0.4136 & & & & \\
\hline $2002 / 8 / 5$ & 14.3 & 0.3915 & Buy 1 more & & 14.3 & & $2003 / 5 / 21$ & 13.35 & 0.3974 & Buy 1 more & & 13.35 & \\
\hline $2002 / 9 / 10$ & 13.15 & 0.4239 & & & & & $2003 / 6 / 13$ & 15.4 & 0.6069 & Sell 4 units & Short & 15.4 & 3.2 \\
\hline $2002 / 9 / 11$ & 12.95 & 0.3882 & Buy 1 more & & 12.95 & & $2003 / 6 / 16$ & 15.4 & 0.5909 & & & & \\
\hline 2002/9/13 & 13.05 & 0.4077 & & & & & 5/17 & 15.6 & 0.6081 & $\begin{array}{l}\text { Short } 1 \\
\text { more }\end{array}$ & & 15.6 & \\
\hline $2002 / 9 / 16$ & 12.6 & 0.3985 & Buy 1 more & & 12.6 & & $2003 / 6 / 19$ & 15.4 & 0.5841 & & & & \\
\hline $2002 / 9 / 20$ & 12.55 & 0.4269 & & & & & $2003 / 6 / 20$ & 15.6 & 0.6177 & $\begin{array}{l}\text { (No new hi } \\
\text { short) }\end{array}$ & & no $n$ & \\
\hline $2002 / 9 / 23$ & 12.35 & 0.3879 & Buy 1 more & & 12.35 & & $2003 / 7 / 2$ & 15.3 & 0.5997 & & & & \\
\hline $2002 / 10 / 9$ & 12.05 & 0.4076 & & & & & $2003 / 7 / 3$ & 16.3 & 0.6308 & $\begin{array}{l}\text { Short } 1 \\
\text { more }\end{array}$ & & 16.3 & \\
\hline $2002 / 10 / 11$ & 11.6 & 0.3984 & Buy 1 more & & 11.6 & & $12 / 3$ & 15.6 & 0.3863 & $\begin{array}{l}\text { Close } 3 \\
\text { units }\end{array}$ & Buy & 15.6 & 0.5 \\
\hline $2002 / 11 / 11$ & 15 & 0.6030 & Sell 6 units & Short & 15 & 11.2 & $12 / 4$ & 15.6 & 0.4097 & & & & \\
\hline $2002 / 11 / 21$ & 15.2 & 0.5830 & & & & & $2003 / 12 / 5$ & 15.6 & 0.3933 & (No new lau & $\mathrm{V} \mathrm{clo}$ & $10 \mathrm{~m}$ & buy) \\
\hline $2002 / 11 / 22$ & 16.2 & 0.6179 & Short 1 more & & 16.2 & & $2004 / 1 / 14$ & 18 & 0.6261 & Sell to close & & & 2.4 \\
\hline & & & & & & & & & & & & profits & 221 \\
\hline
\end{tabular}

Appendix III. Monthly changes of standard deviation

\begin{tabular}{|c|c|c|c|c|c|c|c|c|}
\hline Started & Ended & stdev & Started & Ended & stdev & Started & Ended & stdev \\
\hline $2002 / 2 / 26$ & $2003 / 2 / 14$ & 0.0331 & $2005 / 10 / 15$ & $2006 / 10 / 14$ & 0.0200 & $2009 / 6 / 15$ & $2010 / 6 / 14$ & 0.0149 \\
\hline $2002 / 3 / 15$ & $2003 / 3 / 14$ & 0.0329 & $2005 / 11 / 15$ & $2006 / 11 / 14$ & 0.0193 & $2009 / 7 / 15$ & $2010 / 7 / 14$ & 0.0147 \\
\hline $2002 / 4 / 15$ & $2003 / 4 / 14$ & 0.0316 & $2005 / 12 / 15$ & $2006 / 12 / 14$ & 0.0191 & $2009 / 8 / 15$ & $2010 / 8 / 14$ & 0.0153 \\
\hline $2002 / 5 / 15$ & $2003 / 5 / 14$ & 0.0294 & $2006 / 1 / 15$ & $2007 / 1 / 14$ & 0.0189 & $2009 / 9 / 15$ & $2010 / 9 / 14$ & 0.0164 \\
\hline $2002 / 6 / 15$ & $2003 / 6 / 14$ & 0.0280 & $2006 / 2 / 15$ & $2007 / 2 / 14$ & 0.0181 & $2009 / 10 / 15$ & $2010 / 10 / 14$ & 0.0164 \\
\hline $2002 / 7 / 15$ & $2003 / 7 / 14$ & 0.0279 & $2006 / 3 / 15$ & $2007 / 3 / 14$ & 0.0183 & $2009 / 11 / 15$ & $2010 / 11 / 14$ & 0.0167 \\
\hline $2002 / 8 / 15$ & $200387 / 14$ & 0.0271 & $2006 / 4 / 15$ & $2007 / 4 / 14$ & 0.0183 & $2009 / 12 / 15$ & $2010 / 12 / 14$ & 0.0172 \\
\hline $2002 / 9 / 15$ & $2003 / 9 / 14$ & 0.0272 & $2006 / 5 / 15$ & $2007 / 5 / 14$ & 0.0169 & $2010 / 1 / 15$ & 2011/1/14 & 0.0181 \\
\hline $2002 / 10 / 15$ & $2003 / 10 / 14$ & 0.0265 & $2006 / 6 / 15$ & $2007 / 6 / 14$ & 0.0156 & $2010 / 2 / 15$ & $2011 / 2 / 14$ & 0.0184 \\
\hline $2002 / 11 / 15$ & $2003 / 11 / 14$ & 0.0250 & $2006 / 7 / 15$ & $2007 / 7 / 14$ & 0.0149 & $2010 / 3 / 15$ & $2011 / 3 / 14$ & 0.0189 \\
\hline $2002 / 12 / 15$ & $2003 / 12 / 14$ & 0.0220 & $2006 / 8 / 15$ & $2007 / 8 / 14$ & 0.0163 & $2010 / 4 / 15$ & $2011 / 4 / 14$ & 0.0195 \\
\hline
\end{tabular}




\begin{tabular}{|c|c|c|c|c|c|c|c|c|}
\hline $2003 / 1 / 15$ & $2004 / 1 / 14$ & 0.0218 & $2006 / 9 / 15$ & $2007 / 9 / 14$ & 0.0166 & $2010 / 5 / 15$ & $2011 / 5 / 14$ & 0.0197 \\
\hline $2003 / 2 / 15$ & $2004 / 2 / 14$ & 0.0204 & $2006 / 10 / 15$ & $2007 / 10 / 14$ & 0.0167 & $2010 / 6 / 15$ & $2011 / 6 / 14$ & 0.0194 \\
\hline $2003 / 3 / 15$ & $2004 / 3 / 14$ & 0.0209 & $2006 / 11 / 15$ & $2007 / 11 / 14$ & 0.0168 & $2010 / 7 / 15$ & $2011 / 7 / 14$ & 0.0189 \\
\hline $2003 / 4 / 15$ & $2004 / 4 / 14$ & 0.0226 & $2006 / 12 / 15$ & $2007 / 12 / 14$ & 0.0177 & $2010 / 8 / 15$ & $2011 / 8 / 14$ & 0.0195 \\
\hline $2003 / 5 / 15$ & $2004 / 5 / 14$ & 0.0234 & $2007 / 1 / 15$ & $2008 / 1 / 14$ & 0.0185 & $2010 / 9 / 15$ & $2011 / 9 / 14$ & 0.0201 \\
\hline $2003 / 6 / 15$ & $2004 / 6 / 14$ & 0.0251 & $2007 / 2 / 15$ & $2008 / 2 / 14$ & 0.0202 & $2010 / 10 / 15$ & $2011 / 10 / 14$ & 0.0217 \\
\hline $2003 / 7 / 15$ & $2004 / 7 / 14$ & 0.0244 & $2007 / 3 / 15$ & $2008 / 3 / 14$ & 0.0202 & $2010 / 11 / 15$ & $2011 / 11 / 14$ & 0.0221 \\
\hline $2003 / 8 / 15$ & $2004 / 8 / 14$ & 0.0243 & $2007 / 4 / 15$ & $2008 / 4 / 14$ & 0.0214 & $2010 / 12 / 15$ & $2011 / 12 / 14$ & 0.0223 \\
\hline $2003 / 9 / 15$ & $2004 / 9 / 14$ & 0.0238 & $2007 / 5 / 15$ & $2008 / 5 / 14$ & 0.0222 & $2011 / 1 / 15$ & $2012 / 1 / 14$ & 0.0225 \\
\hline $2003 / 10 / 15$ & $2004 / 10 / 14$ & 0.0239 & $2007 / 6 / 15$ & $2008 / 6 / 14$ & 0.0233 & $2011 / 2 / 15$ & $2012 / 2 / 14$ & 0.0228 \\
\hline $2003 / 11 / 15$ & $2004 / 11 / 14$ & 0.0244 & $2007 / 7 / 15$ & $2008 / 7 / 14$ & 0.0239 & $2011 / 3 / 15$ & $2012 / 3 / 14$ & 0.0223 \\
\hline $2003 / 12 / 15$ & $2004 / 12 / 14$ & 0.0248 & $2007 / 8 / 15$ & $2008 / 8 / 14$ & 0.0241 & $2011 / 4 / 15$ & $2012 / 4 / 14$ & 0.0219 \\
\hline $2004 / 1 / 15$ & $2005 / 1 / 14$ & 0.0248 & $2007 / 9 / 15$ & $2008 / 9 / 14$ & 0.0249 & $2011 / 5 / 15$ & $2012 / 5 / 14$ & 0.0216 \\
\hline $2004 / 2 / 15$ & $2005 / 2 / 14$ & 0.0241 & $2007 / 10 / 15$ & $2008 / 10 / 14$ & 0.0271 & $2011 / 6 / 15$ & $2012 / 6 / 14$ & 0.0218 \\
\hline $2004 / 3 / 15$ & $2005 / 3 / 14$ & 0.0230 & $2007 / 11 / 15$ & $2008 / 11 / 14$ & 0.0283 & $2011 / 7 / 15$ & $2012 / 7 / 14$ & 0.0217 \\
\hline $2004 / 4 / 15$ & $2005 / 4 / 14$ & 0.0212 & $2007 / 12 / 15$ & $2008 / 12 / 14$ & 0.0290 & $2011 / 8 / 15$ & $2012 / 8 / 14$ & 0.0204 \\
\hline $2004 / 5 / 15$ & $2005 / 5 / 14$ & 0.0201 & $2008 / 1 / 15$ & $2009 / 1 / 14$ & 0.0292 & $2011 / 9 / 15$ & $2012 / 9 / 14$ & 0.0194 \\
\hline $2004 / 6 / 15$ & $2005 / 6 / 14$ & 0.0177 & $2008 / 2 / 15$ & $2009 / 2 / 14$ & 0.0285 & $2011 / 10 / 15$ & $2012 / 10 / 14$ & 0.0169 \\
\hline $2004 / 7 / 15$ & $2005 / 7 / 14$ & 0.0170 & $2008 / 3 / 15$ & $2009 / 3 / 14$ & 0.0289 & $2011 / 11 / 15$ & $2012 / 11 / 14$ & 0.0158 \\
\hline $2004 / 8 / 15$ & $2005 / 8 / 14$ & 0.0172 & $2008 / 4 / 15$ & $2009 / 4 / 14$ & 0.0299 & $2011 / 12 / 15$ & $2012 / 12 / 14$ & 0.0145 \\
\hline $2004 / 9 / 15$ & $2005 / 9 / 14$ & 0.0170 & $2008 / 5 / 15$ & $2009 / 5 / 14$ & 0.0309 & $2012 / 1 / 15$ & $2013 / 1 / 14$ & 0.0130 \\
\hline $2004 / 10 / 15$ & $2005 / 10 / 14$ & 0.0161 & $2008 / 6 / 15$ & $2009 / 6 / 14$ & 0.0316 & $2012 / 2 / 15$ & $2013 / 2 / 14$ & 0.0116 \\
\hline $2004 / 11 / 15$ & $2005 / 11 / 14$ & 0.0164 & $2008 / 7 / 15$ & $2009 / 7 / 14$ & 0.0317 & $2012 / 3 / 15$ & $2013 / 3 / 14$ & 0.0116 \\
\hline $2004 / 12 / 15$ & $2005 / 12 / 14$ & 0.0164 & $2008 / 8 / 15$ & $2009 / 8 / 14$ & 0.0309 & $2012 / 4 / 15$ & $2013 / 4 / 14$ & 0.0117 \\
\hline $2005 / 1 / 15$ & $2006 / 1 / 14$ & 0.0163 & $2008 / 9 / 15$ & $2009 / 9 / 14$ & 0.0284 & $2012 / 5 / 15$ & $2013 / 5 / 14$ & 0.0115 \\
\hline $2005 / 2 / 15$ & $2006 / 2 / 14$ & 0.0171 & $2008 / 10 / 15$ & $2009 / 10 / 14$ & 0.0275 & $2012 / 6 / 15$ & $2013 / 6 / 14$ & 0.0108 \\
\hline $2005 / 3 / 15$ & $2006 / 3 / 14$ & 0.0176 & $2008 / 11 / 15$ & $2009 / 11 / 14$ & 0.0261 & $2012 / 7 / 15$ & $2013 / 7 / 14$ & 0.0108 \\
\hline $2005 / 4 / 15$ & $2006 / 4 / 14$ & 0.0171 & $2008 / 12 / 15$ & $2009 / 12 / 14$ & 0.0248 & $2012 / 8 / 15$ & $2013 / 8 / 14$ & 0.0107 \\
\hline $2005 / 5 / 15$ & $2006 / 5 / 14$ & 0.0179 & $2009 / 1 / 15$ & $2010 / 1 / 14$ & 0.0238 & $2012 / 9 / 15$ & $2013 / 9 / 14$ & 0.0104 \\
\hline $2005 / 6 / 15$ & $2006 / 6 / 14$ & 0.0190 & $2009 / 2 / 15$ & $2010 / 2 / 14$ & 0.0234 & $2012 / 10 / 15$ & $2013 / 10 / 14$ & 0.0105 \\
\hline $2005 / 7 / 15$ & $2006 / 7 / 14$ & 0.0197 & $2009 / 3 / 15$ & $2010 / 3 / 14$ & 0.0226 & $2012 / 11 / 15$ & $2013 / 11 / 14$ & 0.0103 \\
\hline $2005 / 8 / 15$ & $2006 / 8 / 14$ & 0.0194 & $2009 / 4 / 15$ & $2010 / 4 / 14$ & 0.0198 & $2012 / 12 / 15$ & $2013 / 12 / 14$ & 0.0102 \\
\hline $2005 / 9 / 15$ & $2006 / 9 / 14$ & 0.0197 & $2009 / 5 / 15$ & $2010 / 5 / 14$ & 0.0173 & $2013 / 1 / 15$ & $2014 / 1 / 14$ & 0.0102 \\
\hline
\end{tabular}

Appendix IV. Information of all standard 3-day co-movement plus phase transition (2008-2012)

\begin{tabular}{|c|c|c|c|c|c|c|c|c|c|c|}
\hline date & $y$ & $y \%$ & $a_{1}$ & $a_{2}$ & $a_{3}$ & $a_{4}$ & $b_{1}$ & $b_{2}$ & $b_{3}$ & $b_{4}$ \\
\hline $2008 / 6 / 3$ & -230.42 & $-2.63 \%$ & 120.55 & 4079.01 & 4724.55 & 1959.14 & 5645.22 & 1716.16 & 1130.49 & 3903.62 \\
\hline $2008 / 8 / 21$ & -34.73 & $-0.50 \%$ & 87.63 & 991.21 & 4370.85 & 457.77 & 4202.15 & 3269.67 & 0 & 3863.73 \\
\hline $2009 / 1 / 15$ & -124.15 & $-2.84 \%$ & 0 & 2159.78 & 2179.8 & 835.51 & 2883.85 & 738.56 & 724.98 & 2063.34 \\
\hline $2009 / 7 / 3$ & 28.58 & $0.43 \%$ & 4024.89 & 4224.53 & 4386.77 & 1648.75 & 534.25 & 347.96 & 206.3 & 2889.5 \\
\hline $2009 / 8 / 20$ & -145.57 & $-2.14 \%$ & 257.97 & 699.79 & 4473.18 & 1082.12 & 4145.55 & 3654.64 & 0 & 3359.79 \\
\hline $2010 / 1 / 13$ & -110.52 & $-1.33 \%$ & 373.35 & 4365.69 & 4728.92 & 1649.89 & 4974.16 & 1021.79 & 691.41 & 3765.76 \\
\hline $2010 / 2 / 1$ & -345.65 & $-4.58 \%$ & 285.58 & 717.89 & 4198.07 & 1048.33 & 4583.47 & 4080.04 & 653.43 & 3799.68 \\
\hline $2010 / 4 / 22$ & -201.74 & $-2.48 \%$ & 1130.9 & 3506.48 & 4955.81 & 895.08 & 4104.75 & 1743.96 & 380.79 & 4425.08 \\
\hline $2010 / 5 / 11$ & -198.07 & $-2.55 \%$ & 168.16 & 2595.75 & 5087.35 & 2204.25 & 4806.17 & 2378.29 & 0 & 2895.41 \\
\hline $2010 / 7 / 12$ & -43.76 & $-0.57 \%$ & 384.29 & 447.92 & 4399.06 & 1161.81 & 4769.84 & 4685.26 & 797.93 & 4042.03 \\
\hline $2010 / 8 / 5$ & -107.22 & $-1.34 \%$ & 678.43 & 4284.81 & 4618.86 & 1108.77 & 4834.43 & 1270.9 & 990.82 & 4471.34 \\
\hline $2010 / 8 / 25$ & -164.1 & $-2.12 \%$ & 0 & 278.84 & 4164.24 & 2078.19 & 5443.23 & 5102.53 & 1262.45 & 3380.17 \\
\hline $2010 / 10 / 12$ & -148.18 & $-1.81 \%$ & 79.81 & 2685.75 & 5138.89 & 1884.4 & 5722.81 & 3159.53 & 782.42 & 4059.44 \\
\hline $2010 / 10 / 18$ & 17.03 & $0.21 \%$ & 0 & 772.96 & 3060.85 & 2401.77 & 5839.76 & 5034.95 & 2769.07 & 3456.53 \\
\hline $2010 / 11 / 15$ & -16.77 & $-0.20 \%$ & 159.19 & 213.33 & 5225.58 & 498.12 & 5792.46 & 5625.48 & 649.5 & 5341.85 \\
\hline $2011 / 1 / 21$ & 0 & $0.00 \%$ & 287.41 & 2063.75 & 3635 & 3124.59 & 5913.86 & 4142.61 & 2596.15 & 3128.41 \\
\hline $2011 / 4 / 19$ & -18.68 & $-0.21 \%$ & 1199.29 & 5435.63 & 5964.42 & 1933.67 & 4839 & 707.66 & 307.52 & 4346.67 \\
\hline $2011 / 11 / 10$ & -105.93 & $-1.41 \%$ & 0 & 4440.53 & 5523.21 & 312.11 & 5382.29 & 987.21 & 0 & 5172.3 \\
\hline $2011 / 12 / 19$ & 0 & $0.00 \%$ & 218.4 & 3410.09 & 4992.9 & 2106.02 & 4649.51 & 1483.39 & 118.1 & 3008.94 \\
\hline $2012 / 2 / 23$ & -4.2 & $-0.05 \%$ & 148.99 & 1025.81 & 5559.92 & 1559.06 & 5642.12 & 4774.73 & 363.62 & 4368.17 \\
\hline $2012 / 4 / 11$ & -143.99 & $-1.86 \%$ & 1297.64 & 2886.55 & 5585.02 & 973.37 & 4198.81 & 2605.01 & 0 & 4580.74 \\
\hline $2012 / 4 / 27$ & -44.54 & $-0.58 \%$ & 3316.1 & 4874.2 & 5524.82 & 2292.67 & 2105.61 & 588.55 & 61.84 & 3276.85 \\
\hline $2012 / 8 / 7$ & -17.28 & $-0.23 \%$ & 4891.13 & 5552.95 & 5690.64 & 2551.47 & 715.81 & 78.7 & 0 & 3120.66 \\
\hline $2012 / 10 / 31$ & -19.78 & $-0.28 \%$ & 2284.45 & 4195.62 & 4663.12 & 2227.24 & 3162.19 & 1247.38 & 812.05 & 3227.77 \\
\hline
\end{tabular}

$t_{1}, t_{2}, t_{3}:$ the first, second and third date., respectively;

$y$ : the high at the fifth day $t_{5}$ minus the close at the fourth day $t_{4}$;

$y \%$ : the percentage of $y$ with respect to the close at $t_{4}$;

$a_{1}, a_{2}, a_{3}, a_{4}$ : the sum of all rising industrial indexes at $t_{1}, t_{2}, t_{3}$ and $t_{4}$, respectively;

$b_{1}, b_{2}, b_{3}, b_{4}$ : the sum of all declining industrial indexes at $t_{1}, t_{2}, t_{3}$ and $t_{4}$, respectively; 